\title{
KAJIAN LITERATUR KONSEP GREEN BUILDING PADA BANGUNAN TROPIS
}

\author{
Amalia Effendy ${ }^{1}$, Mery Silviana ${ }^{2}$ \\ ${ }^{1}$ Universitas Abulyatama, email: amel.arsitektur@gmail.com \\ ${ }^{2}$ Universitas Al Muslim, email: Merysilviana85@gmail.com
}

\begin{abstract}
ABSTRAK
Efek gas rumah kaca dan emisi karbon menjadi isu yang kerap dibincangkan dalam beberapa tahun terakhir. Salah satu point dalam Protokol Kyoto adalah mereduksi efek gas rumah kaca. Pembakaran minyak bumi dan batu bara untuk menghasilkan energi melepaskan karbondioksida $\left(\mathrm{CO}_{2}\right) . \mathrm{CO}_{2}$ yang menumpuk di atmosfir menyebabkan efek gas rumah kaca dan pemanasan global. Total konsumsi energi yang digunakan pada bangunan mencapai $40 \%$ dari keseluruhan penggunaan energi. Penelitian ini bertujuan untuk mengembangkan sebuah konsep desain rumah dengan penggunaan energi yang minimal dengan cara melakukan review terhadap jurnal-jurnal yang dengan tema bangunan hemat energi. Hasil penelitian menemukan bahwa penerapan bangunan hemat energi dapat dilakukan melalui orientasi bangunan dan pemilihan material konstruksi.
\end{abstract}

Kata kunci: efek gas rumah kaca, protokol kyoto, bangunan hemat energi

Info Artikel:

Dikirim: 22 Februari 2021; Revisi: 5 Maret 2021; Diterima: 17 Maret 2021; Diterbitkan: 31 Maret 2021

(C2021 The Author(s). Published by Arsitekno, Architecture Program, Universitas Malikussaleh, Aceh, Indonesia under the Creative Commons Attribution 4.0 International License (https://creativecommons.org/licenses/by/4.0/).

\section{PENDAHULUAN}

Efek gas rumah kaca dan emisi karbon menjadi isu yang kerap dibincangkan dalam beberapa tahun terakhir. PBB melalui UNFCCC (United Nation Framework Convension on Climate Change) telah meratifikasi Protokol Kyoto pada tahun 1998 [1] dan Doha Amandemen [2]. Dengan disahkan Undang-undang No 17 Tahun 2004 [3] maka penerapan Protokol Kyoto secara resmi berlaku di Indonesia. Salah satu butir dalam Protokol Kyoto adalah mereduksi efek gas rumah kaca. Kebutuhan energi saat ini masih tergantung pada sumber energi yang berasal dari fosil, yaitu minyak bumi dan batu bara. UN Habitat [4] menyebutkan bahwa pada 2012 suplai energi global $81,3 \%$ berasal dari bahan bakar fosil ( minyak bumi, gas dan batu bara) $9.7 \%$ berasal dari energi nuklir, dan hanya $9 \%$ berasal dari energi terbarukan (seperti hidro, angin, biomass dan matahari). Pembakaran minyak bumi dan batu bara untuk menghasilkan energi melepaskan karbondioksida $\left(\mathrm{CO}_{2}\right) \cdot \mathrm{CO}_{2}$ yang menumpuk di atmosfir akan menyebabkan efek gas rumah kaca dan pemanasan global. Pada sektor bangunan, total konsumsi energi yang digunakan mencapai $40 \%$ dari keseluruhan penggunaan energi [5].

Banda Aceh adalah sebuah kota yang terletak di daerah tropis dan dikelilingi oleh lautan memiliki suhu udara berkisar antara $24^{\circ} \mathrm{C}$ dipagi hari dan $35^{\circ} \mathrm{C}$ pada siang hari. American Society of Heating, Refrigerating and Air-conditioning Engineers (ASHRAE) Standar 55-2013 menetapkan kenyamanan termal yang direkomendasikan untuk bangunan berkisar antara $67-82^{\circ} \mathrm{F}$ atau setara dengan 19 sampai $27^{\circ} \mathrm{C}$ [6]. Berdasarkan penelitian yang dilakukan oleh Karyono pada tahun 1993 di Jakarta mendapat kesimpulan, bahwa suhu nyaman untuk wilayah Indonesia adalah $24^{\circ} \mathrm{C}$ [7]. Bila merujuk pada standar ini, maka terlihat bahwa suhu udara Kota Banda Aceh berada diatas standar kenyamanan tersebut. Untuk menciptakan kenyamanan termal dan mengatasi suhu udara yang panas, maka penggunaan penghawaan buatan berupa kipas angin dan air conditioning (AC) menjadi pilihan bagi masyarakat. Penggunaan AC dan Kipas angin ini tentunya memerlukan listrik sebagai sumber energi. Dilain pihak, penurunan $1^{\circ} \mathrm{C}$ suhu $\mathrm{AC}$ akan mengakibatkan peningkatan konsumsi listrik 20\% [7]. 
Untuk menciptakan kenyamanan termal dalam ruangan tentunya akan membutuhkan lebih banyak energi listrik. Lee dan Chang menyebutkan bahwa umumnya orang menghabiskan $90 \%$ waktu untuk beraktifitas dalam ruang dibandingkan aktifitas luar ruang [8]. Secara umum, ada tiga cara yang dapat dilakukan untuk menghemat energi dalam bangunan, antara lain [9]:

1. Pemilihan sistem utilitas bangunan (pengkondisian udara, pemilihan lampu)

2. Perilaku pengguna bangunan (penghematan energi secara aktif)

3. Desain bangunan.

Penelitian ini dilakukan untuk menjawab tantangan yang disebutkan diatas dan mengurangi ketergantungan terhadap energi listrik, serta mengembangkan sebuah konsep desain rumah dengan penggunaan energi yang minimal. Pengurangan penggunaan energi pada bangunan dapat dilakukan melalui desain dan material bangunan.

\section{METODE PENELITIAN}

Metodologi yang digunakan dalam penelitian ini adalah metode deskriptif dengan cara kajian pustaka. Olah data dilakukan dengan cara mengumpulkan jurnal-jurnal yang membahas tentang efisiensi energi pada bangunan, dari jurnal tersebut akan diambil data yang mengenai judul, nama peneliti, metode penelitian yang digunakan serta hasil penelitian dari jurnal-jurnal tersebut. Kemudian, kesimpulan diambil mengenai konsep penerapan bangunan ramah energi. Menurut Radolph, dalam sebuah penelitian kajian pustaka berfungsi untuk memberikan sebuah kerangka kerja dan mengaitkan temuan sebelumnya dan temuan baru [10]. Cooper sebagaimana dikutip Radolph mendefinisikan literature review sebagai sebuah kegiatan mengumpulkan dan menganalisa informasi, fokus pada temuan, dan meringkas substansi dari sebuah literatur serta menarik kesimpulan, adapun tahapan kajian pustaka antara lain :

1. Merumuskan masalah

2. Mengumpulkan data

3. Mengevaluasi data

4. Melakukan Analisa dan pembahasan

5. Public presentation

Setelah proses pengumpulan data dilakukan, selanjutnya diambil kesimpulan mengenai konsep penerapan bangunan ramah energi.

\section{HASIL DAN PEMBAHASAN}

Setelah mengumpulkan beberapa penelitian yang membahas mengenai green building, maka diperoleh hasil seperti pada tabel 1 berikut.

Tabel 1. Pustaka Tentang Green Building

\begin{tabular}{|c|c|c|c|}
\hline Nama & Judul & Metode & Hasil \\
\hline $\begin{array}{l}\text { Yuri Hermawan } \\
\text { Prasetyo[11] }\end{array}$ & $\begin{array}{c}\text { Kinerja Bangunan, } \\
\text { Desain Pasif } \\
\text { Berdasarkan Simulasi } \\
\text { Ecotect dan Pengukuran } \\
\text { Lapangan. Studi Kasus : } \\
\text { Bangunan Konvensi } \\
\text { Grha Wiksa Praniti } \\
\text { Bandung }\end{array}$ & komparatif kualitatif & $\begin{array}{l}\text { Konsumsi energi listrik } \\
\text { dapat dikurangi dengan } \\
\text { cara pemanfaatan cahaya } \\
\text { alami serta kenyamanan } \\
\text { termal dapat diciptakan } \\
\text { dengan penggunaan } \\
\text { ventilasi campuran. }\end{array}$ \\
\hline $\begin{array}{l}\text { Yuri Hermawan } \\
\text { Prasetyo dan Sri } \\
\text { Astuti[12] }\end{array}$ & $\begin{array}{c}\text { Ekspresi Bentuk } \\
\text { Klimatik Tropis } \\
\text { Arsitektur Tradisional } \\
\text { Nusantara dalam } \\
\text { Regionalisme }\end{array}$ & deskriptif kualitatif & $\begin{array}{l}\text { Adaptasi terhadap iklim } \\
\text { dilakukan dengan } \\
\text { beragam bentuk atap } \\
\text { rumah. Penggunaan } \\
\text { dinding yang tidak } \\
\text { tertutup rapat berdampak } \\
\text { pada sirkulasi udara dan } \\
\text { pencahayaan alami } \\
\text { bangunan serta bangunan } \\
\text { berbentuk panggung }\end{array}$ \\
\hline
\end{tabular}




\begin{tabular}{|c|c|c|c|}
\hline & & & $\begin{array}{l}\text { merupakan adaptasi } \\
\text { masyarakat Indonesia } \\
\text { terhadap kondisi iklim. }\end{array}$ \\
\hline $\begin{array}{l}\text { Eddy Imam } \\
\text { Santoso[13] }\end{array}$ & $\begin{array}{l}\text { Kenyamanan Termal } \\
\text { Indoor pada Bangunan } \\
\text { di Daerah Beriklim } \\
\text { Tropis Lembab }\end{array}$ & Literature review & $\begin{array}{l}\text { Untuk mencapai } \\
\text { kenyamanan termal yang } \\
\text { diinginkan } \\
\text { dilakukan kontrol atau } \\
\text { tindakan adaptif dari } \\
\text { penghuni diantaranya } \\
\text { dengan mengatur sistem } \\
\text { ventilasi, mengatur } \\
\text { sirkulasi angin secara } \\
\text { mekanik, memberikan } \\
\text { tirai pada bagian } \\
\text { bangunan yang langsung } \\
\text { terkena radiasi matahari } \\
\text { bahkan disarankan untuk } \\
\text { membuat disain perangkat } \\
\text { shading matahari untuk } \\
\text { meminimalkan panas } \\
\text { radiasi. }\end{array}$ \\
\hline $\begin{array}{l}\text { Al-Obaidi, } \\
\text { dkk[14] }\end{array}$ & $\begin{array}{c}\text { Passive Cooling } \\
\text { Techniques Through } \\
\text { Reflective and Radiative } \\
\text { Roof in Tropical Houses } \\
\text { in South East Asia : a } \\
\text { literature review }\end{array}$ & Literature review & $\begin{array}{l}\text { Penggunaaan atap yang } \\
\text { dapat merefleksikan } \\
\text { panas dan radiasi matahari } \\
\text { akan meminimalkan efek } \\
\text { panas. Selain itu, melalui } \\
\text { penggunaan atap tersebut } \\
\text { maka pada siang hari akan } \\
\text { mendapat cahaya alami. } \\
\text { Pengurangan panas pada } \\
\text { bangunan harus dipahami } \\
\text { oleh desainer karena } \\
\text { pemilihan metode yang } \\
\text { tidak sesuai akan } \\
\text { mengurangi kenyamanan } \\
\text { termal pada bangunan. }\end{array}$ \\
\hline
\end{tabular}

\begin{tabular}{|c|c|c|c|}
\hline $\begin{array}{l}\text { Soojung Kim, } \\
\text { dkk [15] }\end{array}$ & $\begin{array}{l}\text { Assessment of the Impact } \\
\text { of Window Size, Position } \\
\text { and Orientation on } \\
\text { Building Energy Load } \\
\text { Using BIM }\end{array}$ & Simulasi & $\begin{array}{l}\text { Ukuran dan posisi jendela } \\
\text { pada bangunan } \\
\text { berpengaruh pada beban } \\
\text { energi yang dikeluarkan } \\
\text { hal ini mengindikasikan } \\
\text { bahwa ukuran jendela } \\
\text { harrus diperhatikan pada } \\
\text { saat mendesain bangunan. }\end{array}$ \\
\hline $\begin{array}{l}\text { Maria } \\
\text { Kolokotroni, } \\
\text { dkk [16] }\end{array}$ & $\begin{array}{l}\text { Cool Roofs: High Tech } \\
\text { Low Cost Solution for } \\
\text { Energy Efficiency and } \\
\text { Thermal Comfort in Low } \\
\text { Rise Low Income Houses } \\
\text { in High Solar Radiation } \\
\text { Countries }\end{array}$ & Eksperimental & $\begin{array}{l}\text { Penggunaan cool paints } \\
\text { pada atap yang tidak } \\
\text { memiliki pemanas secara } \\
\text { signifikan dapat } \\
\text { meningkatkan } \\
\text { kenyamanan termal dan } \\
\text { mengurangi penggunaan } \\
\text { AC didalam rumah. }\end{array}$ \\
\hline
\end{tabular}

\begin{tabular}{|c|c|c|c|}
\hline $\begin{array}{l}\text { Waraporn } \\
\text { Rattanongphisat }\end{array}$ & $\begin{array}{l}\text { Strategi for Energy } \\
\text { Efficient Buildings in } \\
\text { Tropical Climate }\end{array}$ & Case Study & $\begin{array}{l}\text { Orientasi bangunan } \\
\text { kearah cahaya dan mata } \\
\text { angin dapat menetralkan }\end{array}$ \\
\hline
\end{tabular}




\begin{tabular}{|c|c|c|}
\hline $\begin{array}{l}\text { dan Watahnyoo } \\
\text { Rordprapat }[17]\end{array}$ & & $\begin{array}{l}\text { dampak negatif pada } \\
\text { bangunan. Lingkungan } \\
\text { sekitar seperti vegetasi } \\
\text { dan tanaman memberi } \\
\text { keuntungan } \\
\text { ventilasi alami. }\end{array}$ \\
\hline $\begin{array}{l}\text { Harley Troung } \\
\text { and Andrew M. } \\
\text { Gravie }[18]\end{array}$ & $\begin{array}{l}\text { Chifley Passive House : } \\
\text { A case study in energy } \\
\text { efficiency and comfort }\end{array}$ & $\begin{array}{l}\text { Rumah pasif Chifley } \\
\text { secara signifikan lebih } \\
\text { hemat energi daripada } \\
\text { rata-rata rumah sejenis di } \\
\text { kota yang sama, rumah ini } \\
\text { hanya mengkonsumsi } \\
64 \% \text { energi, hal ini terjadi } \\
\text { karena pemanfaatan } \\
\text { matahari dan sistem } \\
\text { ventilasi silang. }\end{array}$ \\
\hline
\end{tabular}

\begin{tabular}{|c|c|c|c|}
\hline $\begin{array}{l}\text { Erlena Perlova, } \\
\text { dkk [19] }\end{array}$ & $\begin{array}{c}\text { Concept Project of Zero } \\
\text { Energy Building }\end{array}$ & Eksperimental & $\begin{array}{l}\text { Mengoptimalkan } \\
\text { orientasi bangunan } \\
\text { menghadap cahaya dan } \\
\text { mempertimbangkan arah } \\
\text { angin untuk menetralisir } \\
\text { efek negatif iklim. }\end{array}$ \\
\hline $\begin{array}{l}\text { Jae Bum Lee, } \\
\text { dkk }[20]\end{array}$ & $\begin{array}{c}\text { An Emperical Study of } \\
\text { Performance } \\
\text { Characterictics BIPV ( } \\
\text { Building Integrated } \\
\text { Photovoltaic) System for } \\
\text { The Realization of Zero } \\
\text { Eneroy Building }\end{array}$ & Eksperimental & $\begin{array}{l}\text { Penggunaan BIPV sistem } \\
\text { menghasilkan surplus } \\
\text { energi sebesar } 664,2 \mathrm{kWh} \text {, } \\
\text { artinya tujuan zero energy } \\
\text { building tercapai melalui } \\
\text { penggunaan BIPV. }\end{array}$ \\
\hline
\end{tabular}

\begin{tabular}{|c|c|c|c|}
\hline $\begin{array}{l}\text { Aidin Nobahar } \\
\text { Sadeghifam, } \\
\text { dkk }[21]\end{array}$ & $\begin{array}{c}\text { Combined Use of Design } \\
\text { of Experimental and } \\
\text { Dynamic Building } \\
\text { Simulation in Assesment } \\
\text { of Energy Efficiency in } \\
\text { Tropical Resedential } \\
\text { Building }\end{array}$ & Simulasi & $\begin{array}{lr}\text { Hasil simulasi dan analisis } \\
\text { energi studi kasus } \\
\text { bangunan menunjukkan } \\
\text { bahwa } & \text { komponen } \\
\text { bangunan } & \text { yang } \\
\text { berpengaruh } & \text { besar } \\
\text { terhadap penghematan } \\
\text { energi adalah dinding, } \\
\text { jendela dan plafon. }\end{array}$ \\
\hline $\begin{array}{l}\text { Y Zhang, dkk } \\
{[22]}\end{array}$ & $\begin{array}{c}\text { A Review of Green } \\
\text { Building Development in } \\
\text { China From the } \\
\text { Perspective of Energy } \\
\text { Saving }\end{array}$ & Literature Review & $\begin{array}{l}\text { Inti dari green building } \\
\text { adalah pelestarian sumber } \\
\text { daya berdasarkan konsep } \\
\text { keberlanjutan dan jenis } \\
\text { desain serta konstruksi } \\
\text { yang digunakan. }\end{array}$ \\
\hline
\end{tabular}

\begin{tabular}{|c|c|c|c|}
\hline $\begin{array}{l}\text { Feng shi. dkk } \\
{[23]}\end{array}$ & $\begin{array}{c}\text { Design Strategies and } \\
\text { Energy Performance of } \\
\text { A Net-zero Energy } \\
\text { House Based on Natural } \\
\text { Philosophy }\end{array}$ & Eksperimental & $\begin{array}{l}\text { Natural living space, } \\
\text { material alamidan natural } \\
\text { family relationship yang } \\
\text { terwujud dari konsep } \\
\text { desain yang berasal dari } \\
\text { filosofi alam } \\
\text { menunjukkan bahwa } \\
\text { strategi desain aktif dan } \\
\text { pasif dapat diterapkan } \\
\text { untuk mencapai }\end{array}$ \\
\hline
\end{tabular}


Konsep utama green building adalah melakukan pengurangan konsumsi energi pada bangunan, khususnya energi yang berasal dari fosil. Konsumsi energi listrik pada bangunan digunakan untuk pencahayaan dan pengudaraan buatan. Untuk meminimalkan penggunaan energi dilakukan dengan menerapkan beberapa kondisi :

- Desain orientasi bangunan, untuk bangunan yang terletak pada daerah tropis, maka orientasi bangunan menghindari cahaya matahari Barat. Hal ini dilakukan untuk menghindari paparan panas matahari yang akan mengakibatkan panas pada bagian dalam bangunan meningkat, sehingga penggunaan sistem pendingin buatan pada bangunan dapat dikurangi.

- Penggunaan ventilasi silang. Ventilasi silang memungkinkan udara mengalir yang akan mendinginkan suhu dalam ruangan, sehingga penggunaan pendingin buatan dapat dihindari.

- Hindari pemilihan material konstruksi pada bangunan yang memberikan efek panas pada bangunan. Penggunaan material yang berasal dari alam, terbukti dapat mengurangi panas pada bangunan.

- Untuk mengurangi penggunaan pencahayaan buatan pada siang hari, dapat dilakukan dengan menempatkan jendela sebanyak mungkin, sehingga cahaya matahari dapat menjangkau setiap bagian bangunan.

\section{KESIMPULAN DAN SARAN}

Konsep green building yang bertujuan untuk mengurangi penggunaan energi yang berasal dari energi fosil dapat diterapkan desain orientasi bangunan, pemilihan material konstruksi bangunan, penggunaan cahaya dan penghawaan alami. Melalui penerapan konsep tersebut diharapkan konsumsi energi listrik yang berasal dari fosil dapat diminimalkan.

\section{DAFTAR PUSTAKA}

[1] UNFCCC, “United Nations Kyoto Protocol," pp. 1-24, 1997.

[2] UNFCCC, "Doha Amendment to the Kyoto Protocol," Unfccc, p. 41, 2012, [Online]. Available: https://unfccc.int/kyoto_protocol/doha_amendment/items/7362.php\%5Cnhttps://treaties.un.org/do c/Publication/CN/2012/CN.718.2012-Eng.pdf.

[3] P. R. Indonesia, “Undang-Undang Republik Indonesia Nomor 17 Tahun 2004 Tentang Pengesahan Kuoto Protocol to the united nations framewrok convention on climate change," Nasional, pp. 16, 2004.

[4] O. Golubchikov and A. Badyina, Sustainable Housing for Sustainable Cities, no. October. 2012.

[5] IEA and UNEP, 2019 Global Status Report for Buildings and Construction: Towards a zeroemissions, efficient and resilient buildings and constructi on sector, vol. 224. 2019.

[6] ASHRAE, "ASHRAE Technical FAQ 92: What are the recommended indoor temperature and humidity levels for homes?," pp. 1-2, 2013, [Online]. Available: https://www.ashrae.org/File Library/Technical Resources/Technical FAQs/TC-02.01-FAQ-92.pdf.

[7] T. H. Karyono, "Arsitektur, kenyamanan termal dan energi," no. November, pp. 1-5, 1996, [Online]. Available: https://www.researchgate.net/publication/305186728.

[8] S. C. Lee and M. Chang, "Indoor and outdoor air quality investigation at schools in Hong Kong," Chemosphere, vol. 41, no. 1-2, pp. 109-113, 2000, doi: 10.1016/S0045-6535(99)00396-3.

[9] T. H. Karyono, "Bangunan hemat energi," no. 8, p. 40561, 2016.

[10] J. J. Randolph, "A guide to writing the dissertation literature review," Pract. Assessment, Res. Eval., vol. 14, no. 13, 2009.

[11] Y. H. Prasetyo, "DAN PENGUKURAN LAPANGAN STUDI KASUS: BANGUNAN KONVENSI GRHA WIKSA PRANITI BANDUNG Building Performance of Passive Design Based on Ecotect Simulation and Field Measurement Case Study : Convention Center Building Grha Wiksa Praniti Bandung," vol. 9, no. 1, pp. 41-53, 2014.

[12] Y. H. Prasetyo et al., "NUSANTARA DALAM REGIONALISME Tropic Climate Form of PROGRAM STUDI ARSITEKTUR UNIVERSITAS MALIKUSSALEH 
Nusantara Traditional Architecture 's Expression in Regionalism," vol. 12, no. 2, pp. 80-93, 2017.

[13] E. I. Santoso, "KENYAMANAN TERMAL INDOOR PADA BANGUNAN DI DAERAH BERIKLIM TROPIS LEMBAB,” pp. 13-19, 1982.

[14] K. M. Al-Obaidi, M. Ismail, and A. M. Abdul Rahman, "Passive cooling techniques through reflective and radiative roofs in tropical houses in Southeast Asia: A literature review," Front. Archit. Res., vol. 3, no. 3, pp. 283-297, 2014, doi: 10.1016/j.foar.2014.06.002.

[15] S. Kim, P. A. Zadeh, S. Staub-French, T. Froese, and B. T. Cavka, "Assessment of the Impact of Window Size, Position and Orientation on Building Energy Load Using BIM," Procedia Eng., vol. 145, no. December, pp. 1424-1431, 2016, doi: 10.1016/j.proeng.2016.04.179.

[16] M. Kolokotroni et al., "Cool roofs: High tech low cost solution for energy efficiency and thermal comfort in low rise low income houses in high solar radiation countries," Energy Build., vol. 176, no. July, pp. 58-70, 2018, doi: 10.1016/j.enbuild.2018.07.005.

[17] W. Rattanongphisat and W. Rordprapat, "Strategy for energy efficient buildings in tropical climate," Energy Procedia, vol. 52, pp. 10-17, 2014, doi: 10.1016/j.egypro.2014.07.049.

[18] H. Truong and A. M. Garvie, "Chifley Passive House : A Case Study in Energy Efficiency and Comfort ScienceDirect ScienceDirect ScienceDirect ScienceDirect Chifley Passive House : A Case Study in Energy Efficiency and Comfort Chifley Passive House: A Case Study in Energy Efficiency a," Energy Procedia, vol. 121, no. June, pp. 214-221, 2019, doi: 10.1016/j.egypro.2017.08.020.

[19] E. Perlova, M. Platonova, A. Gorshkov, and X. Rakova, "Concept project of zero energy building," Procedia Eng., vol. 100, no. January, pp. 1505-1514, 2015, doi: 10.1016/j.proeng.2015.01.522.

[20] U. C. Shin, “An empirical study of performance characteristics of BIPV ( Building Integrated Photovoltaic ) system for the realization of zero energy building q," Energy, vol. 66, pp. 25-34, 2014, doi: 10.1016/j.energy.2013.08.012.

[21] A. N. Sadeghifam, S. M. Zahraee, M. M. Meynagh, and I. Kiani, "Combined use of design of experiment and dynamic building simulation in assessment of energy efficiency in tropical residential buildings," Energy Build., vol. 86, pp. 525-533, 2015, doi: 10.1016/j.enbuild.2014.10.052.

[22] Y. Zhang, J. Kang, and H. Jin, "A review of green building development in China from the perspective of energy saving," Energies, vol. 11, no. 2, 2018, doi: 10.3390/en11020334.

[23] F. Shi, S. Wang, J. Huang, and X. Hong, "Design strategies and energy performance of a net-zero energy house based on natural philosophy," J. Asian Archit. Build. Eng., vol. 19, no. 1, pp. 1-15, 2020, doi: 10.1080/13467581.2019.1696206. 